\title{
PAULO MEKSENAS E A HERANÇA DO PENSAMENTO MODERNO ${ }^{1}$
}

\author{
PAULO MEKSENAS AND THE MODERN THOUGHT HERITAGE \\ PAULO MEKSENAS Y LA HERENCIA DEL PENSAMIENTO MODERNO
}

Jéferson Silveira Dantas*

jeferson.dantas@ufsc.br

\begin{abstract}
RESUMO: o presente texto apresenta a vida e a obras de Paulo Meksenas, educador da UFSC, dando ênfase à sua trajetória e produção acadêmica. O autor é apresentado como um sociólogo filiado à teoria marxista e teve sua militância ligada à igreja católica progressista, às pastorais sociais, às CEBs, a Teologia da Libertação e aos partidos de esquerda. O texto ainda detalha a atuação do educador na pesquisa e atividade acadêmica, sendo a função de educador a experiência que o definia por excelência.
\end{abstract}

Palavras-chave: Militância. Educação. Sociologia.

ABSTRACT: This article presents Federal University of Santa Catarina (UFSC) educator's Paulo Meksenas life and work, aiming his journey and academic production. Paulo was a psychologist affiliated to the Marxist theory who operated as a militant linked to the progressive Catholic Church, Basis Ecclesial Communities (CEBs), Liberation Theology and left-wing parties. Further details involving his actuation in research and academic activities are exposed, once his experience as an educator is what defines him the most.

Keywords: Militancy. Education. Sociology.

RESUMEN: El texto presenta la vida y las obras de Paulo Meksenas, educador de la UFSC, dando énfasis a su trayectoria y producción académica. El autor es presentado como un sociólogo, afiliado a la teoría marxista que tuvo su militancia vinculada a la iglesia católica progresista, a las pastorales sociales, a las CEBs, a la teología, a la liberación y a los partidos de izquierda. El texto también detalla el papel del educador en la actividad académica y de investigación, siendo que como educador su experiencia era definida por excelencia.

Palabras clave: Militancia. Educación. Sociología. 
* Historiador e Doutor em Educação pela Universidade Federal de Santa Catarina. Professor no Departamento de Estudos Especializados em Educação do Centro de Ciências da Educação da UFSC. Coordenador do Curso de Pedagogia da UFSC (2015-2017).

${ }^{1}$ Praticamente todas as passagens deste texto foram literariamente retiradas de determinados trechos da obra A modernidade no pensamento de Paulo Meksenas, organizada pelos professores Jéferson Silveira Dantas, Ione Ribeiro Valle, Paula de Abreu Pereira e Renata Ferreira da Silva, publicada pela Editora Insular, na cidade de Florianópolis, no primeiro trimestre de 2015. Agradeço, assim, imensamente a contribuição direta e afetiva dos professores Adriano Duarte e Celso Carminati, amigos íntimos do homenageado, na composição deste texto em memória do professor Meksenas. Para que a redação ficasse mais fluida, evitamos as diversas citações, que poderiam, porventura, tornar o texto muito truncado e tedioso. Agradecemos também à esposa e companheira de Paulo Meksenas, Mariza, e ao seu filho, Rafael, a oportunidade de conhecermos um pouco mais de perto a intimidade do nosso homenageado.

\section{INTRODUÇÃO}

No dia 22 de junho de 2009 fomos surpreendidos com a morte prematura do professor Paulo Meksenas (19602009), docente do Departamento de Estudos Especializados em Educação do Centro de Ciências da Educação da Universidade Federal de Santa Catarina desde 1994. Meksenas nos deixou um legado fundamental, especialmente no que tangia à perspectiva militante do fazer pedagógico, algo que se refletia de maneira intensa em suas palestras e seminários. Não por acaso, suas aulas representavam encontros seminais referentes às problematizações epistemológicas no campo educacional, tanto na graduação quanto na pós-graduação.

Precoce também foi a sua produção acadêmica. Um de seus livros mais conhecidos e adotados no então $2^{\circ}$ grau e Cursos de Magistério de nível médio era Aprendendo Sociologia, a paixão de conhecer a vida, publicado quando o autor tinha pouco mais de vinte anos. Além deste, publicou Educação e Sociedade (2005), Cidadania, Poder e Comunicação (2002), Pesquisa social e Ação Pedagógica: conceitos, métodos e práticas (2001), dentre outros. Meksenas era Bacharel e Licenciado em Ciências Sociais pela Universidade de São Paulo (USP), além de Mestre em Didática e Doutor em Educação pela mesma universidade.

Filho de imigrantes provenientes do leste europeu, sua formação se iniciou em casa, cujo pai, Julius Meksenas, era ávido leitor. A origem familiar era de base operária, que remontava aos princípios sociais defendidos na Revolução Russa em 1917. Participou ativamente dos grupos de jovens da Igreja Católica (Pastoral da Juventude) na zona leste de São Paulo, quando ainda era estudante de Ciências Sociais e das bases militantes do Partido dos Trabalhadores (PT) na década de 1980, em pleno processo de redemocratização do Brasil. Em sua formação acadêmica, comprometida com a militância política e intelectual, os estudos do filósofo italiano Antônio Gramsci (1891-1937) se sobressaíam.

O Parque São Lucas, onde se criou, era um bairro tipicamente operário na zona leste da cidade de São Paulo. Como tantos outros bairros operários da cidade, o Parque São Lucas se ampliara depois da $2^{\mathrm{a}}$ Guerra Mundial, com a chegada dos migrantes mineiros, baianos, cearenses, alagoanos, além de moradores provenientes do interior do próprio estado de São Paulo. Havia também, em menor número, as famílias de imigrantes, instaladas no bairro antes da década de 1950: famílias japonesas; algumas famílias palestinas; sírios e libaneses, que eram proprietários de pequenas lojas na Avenida São Lucas, a principal do bairro; portugueses, espanhóis e "hungareses". Hungarês era o nome genérico atribuído aos imigrantes russos, lituanos, alemães e originários do leste da Europa. Paulo Meksenas era filho de um casal de lituanos - Julius e Aldonia - que chegara ao Brasil no período entre guerras. 
A experiência fabril, e o que se poderia chamar de cultura operária, moldou as sociabilidades e os afetos dos jovens que ali cresceram na década de 1970. O ano de 1978 foi, em vários aspectos, decisivo para os jovens daquele bairro. Primeiro, porque muitos dos moradores do bairro estiveram diretamente envolvidos nas grandes greves daquele período. É bem possível que os mais velhos percebessem que aquilo que para a juventude era a explosão de uma nova forma de participação política - uma verdadeira janela para a cidadania e para o mundo adulto da política - tivesse sido gestado há anos nas Comunidades Eclesiais de Base (CEBs) e nas associações de moradores. Paulo Meksenas participava intensamente das atividades de um grupo de jovens da CEB na igreja de São Felipe Neri, a principal do bairro. E foi lá, certamente, que iniciou suas atividades políticas. A ação política e a fundação do núcleo de base de um partido de trabalhadores foi o caminho daqueles que, no âmbito da igreja progressista, associada à Teologia da Libertação, responderam favoravelmente ao movimento operário organizado.

Muitos tiveram sua primeira experiência eleitoral no pleito para o governo do estado de São Paulo, em 1982. Foi nesse contexto que o bairro, a cidade e o país pareceram ter emergido como um enigma a ser desvendado, alimentando uma profunda vontade de compreensão do mundo ao redor e o enorme desejo de mudança!

Assim, a educação e a formação intelectual e política tornaram-se decisivas para Paulo Meksenas. A ausência de atividades culturais no bairro e as escolas públicas de qualidade sofrível tornavam-se mais evidentes quanto maiores eram os desafios aos quais a juventude se propunha. Poucos tinham a sorte de ter na família alguém curioso ou leitor regular, que pudesse atenuar suas limitações. No caso do Paulo, além do pai, seu irmão mais velho foi esta importante referência afetiva e intelectual.

As frustrações na tentativa de criar um curso de alfabetização para adultos, inspirado na concepção pedagógica de Paulo Freire (1921-1997), levaram vários daqueles jovens do Bairro São Lucas a aspirar à entrada na universidade como caminho necessário para incrementar a formação. Para a maioria, a universidade era algo muito distante. Muitos sequer haviam chegado perto da Cidade Universitária, do outro lado da cidade, na zona oeste. A opção de Paulo Meksenas pelo Curso de Ciências Sociais da USP foi construída nesses termos e para superar essas barreiras que pareciam instransponíveis. A Sociologia da Educação emergiu como o grande tema de estudos e a preocupação central na sua formação acadêmica. Desde sempre ele se definiu como professor, antes de tudo o mais. Gostava de ser visto assim, "apenas" como professor. Passava longo tempo preparando seus cursos, fazendo questão de escrever suas aulas. Isso orientava suas reflexões e facilitava seus encadeamentos lógicos. Muitas dessas aulas viraram livros, vastamente adotados no Ensino 
${ }^{2}$ As passagens referentes ao processo de escolarização na Educação Básica do professor Paulo Meksenas são provenientes de uma entrevista concedida pelo sociólogo à pedagoga Simone de Castro Kuhnen, em julho de 2004. Esta entrevista não se encontra no livro organizado em homenagem a Meksenas, citado anteriormente.
Médio. Escrevia fácil e detestava quem escrevia difícil. Ficava particularmente irritado com uma prática muitíssimo disseminada na universidade: a de considerar as aulas como o "osso duro de roer" do ofício do intelectual, entendendo artigos, livros, conferências, encontros e simpósios como as atividades mais importantes. Exatamente por isso é que participava pouco de eventos acadêmicos aos quais o comparecimento é mais para se fazer visto do que para ver e ouvir realmente - e menos ainda das atividades administrativas, para as quais, diga-se de passagem, nunca teve muita paciência nem talento. Sentia-se incomodado com disputas internas, tão comuns à vida universitária, com favorecimento de grupos de docentes e seus alunos em detrimento de outros, práticas quase sempre distantes de qualquer debate acadêmico intelectual relevante, mas importantíssimas quando se trata de aumentar espaços de influência, o número de bolsas e orientandos, reforçando o toma lá dá cá.

Por isso, Paulo Meksenas foi, antes de tudo, um professor na ampla acepção da palavra. Certa vez, ele se apresentou: "eu não sou um intelectual, eu sou um professor". Não havia nessa frase nenhum desprezo por outras atividades intelectuais, mas o reconhecimento de que ele se realizava dando aulas, que a sala de aula era o local em que se sentia bem, era onde imaginava poder fazer alguma diferença. Aula não era, para ele, o osso duro do ofício, como se fosse um ônus para poder estar na universidade. Não! Lecionar era a melhor parte. Primeiro, porque era o momento em que ele estudava, arrumava as ideias e aprendia coisas novas; segundo, porque tinha um prazer especial com as descobertas de seus alunos. As publicações, os encontros, os simpósios, as conferências eram apenas o resto, a parte menos importante, aquela que ia para o Currículo Lattes.

O processo de escolarização² de Paulo Meksenas, porém, antes de seu ingresso na USP, não foi fácil. Realizou, primeiramente, a $4^{\mathrm{a}}$ série na escola José S. Dias, no mesmo bairro em que morava. O seu pai, que era torneiro mecânico, desejava colocá-lo, posteriormente, numa escola melhor para fazer o ginásio, já que o período aqui assinalado era anterior à reforma educacional ocorrida durante a Ditadura Civil-Militar, que instaurou a reforma do $1 .^{\circ}$ e $2 .^{\circ}$ graus por meio da Lei 5.692/1971. Assim, Meksenas viria a estudar na mesma escola que o seu irmão, cinco anos mais velho, estudava, num bairro um pouco mais afastado, a Vila Zelina, conhecido pela típica culinária lituana.

Contudo, ao término da $4 .^{\mathrm{a}}$ série, na fase de exames finais da então denominada escola primária, a mãe de Meksenas, Aldonia, conversou com o professor regente da turma e lhe disse que o seu filho, no próximo ano, estudaria na escola São Miguel Arcanjo. O professor, então, tentou demovê-la da ideia, porque não haveria mais exame de admissão com a reforma educacional de 1971. Mas a mãe de Meksenas foi enfática e decidiu que o filho faria mais um ano de curso preparatório, pois entendia que o seu 
rendimento escolar não estava adequado. Aos 11 anos, Meksenas realizou seis meses de um curso de admissão no mesmo bairro em que morava e os outros seis meses no curso de admissão da escola São Miguel Arcanjo, mantida por freiras franciscanas e localizada no bairro Zelina.

Na escola São Miguel Arcanjo, no período preparatório, Meksenas foi aluno de uma professora extremamente rigorosa e tradicional. Meksenas admitia que não gostava da escola, que a mesma "era um fardo"! No dia da prova de admissão, Meksenas não foi nada bem, porém, foi aprovado, já que as "provas de admissão" eram refutadas desde a implementação da Lei 5.692/1971. Logo, tornar-se-ia aluno da escola São Miguel Arcanjo, a partir de 1972.

Meksenas procurou ser um estudante aplicado. Sentava-se nas primeiras carteiras e ganhou a confiança da professora de Matemática. Porém, não conseguia compreender a "matéria" e só "tirava zero em Matemática". Acreditava que só "tinha passado de ano", porque tinha fama de aluno comportado. Anos mais tarde, Meksenas reconheceria que os professores daquela escola tinham pouca preparação didática. As aulas de História, por exemplo, eram maçantes. Não passavam de meros resumos de livros didáticos. Por outro lado, as aulas de Português marcaram-lhe muito, pois o professor solicitava muitas redações, aprimorando a escrita dos/as estudantes.

Naquele momento histórico, em que não se solicitava mais "exames de admissão" para o ingresso no ginásio, Meksenas percebia também o quanto as desigualdades econômicas se expressavam em desigualdades escolares, pois na escola São Miguel Arcanjo, Meksenas era o "pobrezinho da sala e os outros eram filhos de engenheiros, de comerciantes" e ele, filho de um operário, ainda que isso não fosse apreendido como um "problema" na relação com os seus colegas.

Foi apenas na etapa final do então $1 .^{\circ}$ grau, na $8 .^{a}$ série, que Meksenas melhorou as suas notas. A principal ruptura que enfrentou entre o término da $4 \cdot^{\mathrm{a}}$ para a $5 \cdot^{\mathrm{a}}$ série, segundo as suas palavras, foi que antes ia a pé para a escola e, depois, precisava tomar um ônibus para chegar à unidade de ensino. $\mathrm{O}$ número de professores também havia aumentado e isto criava novas responsabilidades diante das etapas de aprendizagem. Curiosamente, em 1987, Paulo Meksenas retornaria para a escola São Miguel Arcanjo, mas agora na condição de professor, num período de dois anos. Foi também o momento de reencontro com o seu antigo professor de Português, que tanto lhe marcou em seu processo de escolarização.

Meksenas teve experiências também na condição de professor com o ensino supletivo, além de ter trabalhado durante um curto período (um mês) com crianças de $1 .^{\mathrm{a}}$ a $4{ }^{\mathrm{a}}$ séries, notadamente das periferias de São Paulo, que apresentavam trajetórias de repetências, por meio de um projeto da Fundação Carlos Chagas, onde era assistente de pesquisa. Contudo, suas maiores experiências após a sua 
formação acadêmica na USP foi em cursos supletivos, anos finais do $1 .^{\circ}$ grau e no $2 .^{\circ}$ grau.

Ainda durante a infância, seu sonho era ser aviador. Só que o seu irmão dizia que para ser piloto de avião tinha que ter boas notas em Matemática. E para piorar, na $5 .^{\mathrm{a}}$ série apareceu o problema da miopia. No ensino de $2 .^{\circ}$ grau se interessou pelos cursos técnicos, ingressando na escola técnica de agropecuária na cidade de Jacareí, a 80 quilômetros de São Paulo. O ensino não era muito bom, mas "profissionalizava". Meksenas chegou a pensar em fazer Agronomia, mas como não gostava das disciplinas de Química, Física e Biologia, abandonou a ideia.

Foi o seu irmão, Eduardo, que mais uma vez lhe instigou a buscar o que realmente lhe interessava em termos de estudos e de processo formativo. Meksenas respondeu ao irmão que estava gostando de ler um livro de Caio Prado Júnior (História Econômica do Brasil). Então, Eduardo lhe disse: "Por que você não faz Sociologia"? E aí um dia o irmão lhe trouxe um caderninho, porque ele estava terminando o Curso de Letras na USP, que tinha as disciplinas do Curso de Ciências Sociais. Meksenas ficou fascinado com os temas das disciplinas e a possibilidade de discutir política, já que o seu pai era operário e simpatizante do ideário comunista.

Assim, Meksenas realizou um ano de pré-vestibular no Cursinho "Equipe", que era muito interessante no final da década de 1970. O professor de História de Meksenas em 1979 foi José Genuíno, que acabara de ser anistiado pela sua participação na Guerrilha do Araguaia, entre as décadas de 1960 e 1970. O Cursinho "Equipe" era mais de esquerda e quem cuidava da parte cultural era o hoje apresentador, Serginho Groisman, responsável por trazer filmes políticos proibidos para amplo debate, como era o caso do filme $O$ encouraçado Potemkin (1925), de Sergei Einsenstein (1898-1948). Paulo Meksenas se dedicava aos estudos 10 horas por dia, período que ele mesmo reconheceu de grande aprendizagem e de revisão de todo o primeiro e segundo graus. Assim, Meksenas prestou vestibular e conseguiu uma vaga no Curso de Ciências Sociais da USP.

Paulo Meksenas, como muitos estudantes de sua condição social, teve de conciliar estudos e trabalho. Lecionava e fazia a faculdade. Foi aí que se "descobriu" professor! Segundo as palavras de seu irmão, Eduardo:

O Paulo foi essencialmente um professor. Sua vocação estava entranhada no magistério, tudo o que pensava e fazia tinha como horizonte último, instintivamente, a educação. E sempre foi assim, desde a adolescência/ juventude, quando participava da Pastoral de Juventude do Parque São Lucas e da Zona Leste de São Paulo seguindo a linha teológica da Libertação, animando a formação de Comunidades Eclesiais de Base, motivando as mobilizações para apoio às greves dos metalúrgicos de São Bernardo e vendo formar-se o embrião do que viria a ser o PT, e dando 
sua contribuição à formação do Núcleo do PT do Parque São Lucas, utopia de esperança democrática real. Exercia uma liderança que agregava pessoas, impulsionando-as a refletir sobre situações e maneiras de modificá-las, delegando tarefas, repartindo atribuições, compartilhando responsabilidades. É verdade que sempre procurou ligar-se a pessoas que também eram líderes por natureza, jovens cheios de idealismo e ávidos de saber e fazer: esse grupo de jovens distribuídos entre pastorais, CEB's e PT foi a fina flor de uma geração que deixou sua marca histórica na região. Neste aspecto, ele foi um privilegiado, pois contou com a parceria de 15 ou 20 pessoas excepcionais, raras de se ver hoje em dia, em termos de ideal e abnegação, e todos apenas na casa dos 15 aos 25 anos! Eram os anos finais da década de 70 e início dos 80 . (MEKSENAS, 2009, p. 34).

Já em seu período em Florianópolis, na década de 1990, Paulo Meksenas contribuiu muito com a formação de professores da rede municipal de ensino, especialmente durante a época em que a prefeitura foi governada pela Frente Popular (1993-1996), único governo de esquerda até os dias de hoje. A vinda de sua família para Florianópolis foi decorrente de sua aprovação em concurso público para a Universidade Federal de Santa Catarina (UFSC), o que o posicionou na condição de dedicar-se mais às atividades de pesquisa.

Dentre suas últimas pesquisas, podemos destacar: Pedagogia da Ação Política Popular: duas histórias de militâncias, nos anos de 2001 a 2003; Modernidade e Educação - O Ibero-americanismo e algumas ideias pedagógicas, nos anos de 2004 a 2006; Modernidade e pedagogia no jesuíta Antonio Vieira - análise de alguns sermões, nos anos de 2006 a 2008 e Euclides da Cunha: a ciência como Pedagogia da Militância, iniciada no ano de 2008 e não concluída, em decorrência de seu falecimento. No curso de Mestrado em Educação sua pesquisa voltou-se para compreender as relações entre a produção do livro didático e o Estado.

Além de ter sido um estudioso dos autores clássicos e contemporâneos da Sociologia, Paulo Meksenas era um profundo conhecedor dos grandes filósofos ocidentais. Seu interesse pela filosofia amplia-se a partir das suas atividades como professor de Filosofia da Educação no curso de graduação de Pedagogia e de Epistemologia no Programa de Pós-Graduação em Educação da UFSC. Embora conhecesse diversos autores da Filosofia Antiga, sua especialidade era o pensamento moderno, locus de formação dos grandes clássicos do pensamento sociológico. Pode-se dizer que muitas de suas posições colocavam em xeque, ou em dúvida o seu dizer sobre a realidade, e isto não foi diferente em relação às muitas concepções ou doutrinas sociológicas e filosóficas. 
Ao se referir à vida acadêmica universitária e às suas práticas em decisões em torno da avaliação e aprovação da produção e de projetos de pesquisa, Meksenas não poupou críticas a este universo, principalmente àqueles/as que, revestidos/as de uma aura legitimada pelas escolhas pessoais, se cercam de grupos de interesses e determinam políticas que resultam em processos viciados, tanto no ensino quanto na pesquisa.

Esta realidade, já estudada e denunciada por diversos autores, mas ainda fundante das relações acadêmicas, sobretudo as da Pós-Graduação, coloca em evidência que o discurso crítico quando se corporifica, muitas vezes assume um lugar distante de sua formulação inicial. Por esta razão, Paulo Meksenas tomou o cuidado de separar o que foi e continua sendo a teoria crítica, sobretudo marxista e a prática de professores ou militantes que se revestem deste lugar para legitimarem seus fazeres e pactos com as políticas quantitativistas impostas pelas agências de financiamento e avaliação da produção acadêmica.

Em tempos de profundo relativismo diante dos fenômenos sociais e uma desistoricização preocupante, Eduardo Meksenas localiza ainda o que seriam os últimos projetos de seu irmão antes de seu falecimento.

Ultimamente vinha interessando-se por alguns temas e projetos específicos, desenvolvendo-os lentamente, 'ao sabor do tempo disponível': 1) estava interessado em desvelar a ocorrência histórica de aspectos característicos da Modernidade em momentos anteriores à Modernização clássica e aos Modernismos que foram sua expressão cultural; 2) buscava perscrutar expressões de modernidade presentes em aspectos da tradição cultural popular e resquícios folclóricos ainda vigentes por alguns rincões regionais interioranos; 3) queria estabelecer objetiva e definitivamente o conflito insolúvel existente entre Moral e Moralidade na obra de Fiódor Dostoievski, demonstrando que a ética cristã do autor era insuficiente para solucionar tal conflito. Em relação ao primeiro item apegou-se a Antonio Vieira, cuja formação, atividade e cosmopolitismo tornavam-no figura ímpar em sua época, encerrando em si as contradições e turbilhão típicos da modernidade: homem de Estado de um reino absolutista em decadência, religioso evangelizador numa colônia escravocrata, intelectual dilacerado por um nacionalismo que perdia seu brilho tirando sua riqueza através de um modo de produção francamente anticristão no aspecto moral e já insuficiente no aspecto econômico. (MEKSENAS, 2009, p. 36-38).

As interfaces entre Literatura e História passaram a fazer parte das pesquisas de Paulo Meksenas nos últimos anos, tendo no pensamento moderno as genealogias dos grandes embates políticos, econômicos e culturais. Meksenas tinha em mente ainda caracterizar o marxismo de Sartre 
e como ele se posicionava na tradição marxista. Em sala de aula, o seu tão importante território de trabalho e de pesquisa, lidava com diversas categorias de análise provenientes do marxismo, tais como o conceito de "totalidade" em Luckács; de "ideologia" em Althusser; de "história" em Benjamin; de "modernidade" em Berman e Harvey, sempre em franca discussão com os estudos marxianos, especialmente os Manuscritos Econômico-Fỉlosóficos, a Ideologia Alemã, O 18 brumário de Luís Bonaparte e o Livro I de O Capital.

Por fim, registramos também que os recursos pedagógicos que o professor Meksenas distribuía em todas as aulas (sínteses esquemáticas), auxiliavam seus estudantes na apreensão de uma obra ou de uma categoria de análise específica, pois assim conhecia-se a lógica do pensamento de cada autor estudado, o que Meksenas denominava de "diferentes pontos de vista”. Ele estava sempre disponível para uma conversa ou intercâmbio de textos e livros, além de exemplarmente preparado para conduzir os debates a partir de intervenções qualificadas, ampliando as possibilidades de interpretação sobre um determinado autor ou eixo temático. Tinha coerência e convicção no que ensinava. Exigia a leitura e o compromisso do grupo sem ser autoritário.

Meksenas, além de um grande educador e pesquisador, conseguia com rara qualidade apresentar fundamentações teóricas e metodológicas com um didatismo contagiante. Envolvia-se com o grupo, criava vínculos, expressava-se com indignação, o que o tornava ainda mais próximo dos estudantes, revelando sua humanidade. Diante de um "irrefletido" destempero, desculpava-se imediatamente, sem saber que o seu destempero e indignação era o que mobilizava o grupo de estudantes da graduação ou da pós-graduação, pois o bom educador não foge dos enfrentamentos, ainda que isto signifique demarcar conflitos pontuais com colegas de profissão, sistemas de ensino, lógicas de avaliação arbitrárias em larga escala e verticalizadas etc.

Numa de suas últimas aulas na disciplina de Epistemologia da Educação, a acolhida dos estudantes foi emocionante. Ainda que não se tivesse certeza de que se tratava de uma despedida sem volta, Paulo Meksenas pôde em vida receber o carinho e a admiração de um grupo de pesquisadores/as em formação. Certamente, estes pesquisadores levaram/levarão adiante os seus ensinamentos, e a perenidade de sua obra já se encontra entre nós como uma preciosa herança!

\section{REFERÊNCIAS}

DANTAS, Jéferson Silveira et al. (Orgs). A modernidade no pensamento de Paulo Meksenas. Florianópolis: Insular, 2015.

MEKSENAS, Eduardo. Pensamento e Compromisso: Paulo Meksenas - um esboço de figura. Revista Espaço Acadêmico, ano IX, n. 98, jul. 2009. 